\title{
EL PROCESO DE INTEGRACIÓN SOCIAL DE LOS REFUGIADOS PALESTINOS REASENTADOS EN REGIÓN DE VALPARAÍSO, CHILE
}

\section{Social integration process of the Palestinian refugee resettled in Valparaíso Region, Chile}

Karina Bijit Abde ${ }^{1}$

Universidad de Valparaíso, Valparaíso, Chile.

Recibido: 31 de mayo de 2011. Aprobado: 26 de septiembre de 2011.

\section{RESUMEN}

La experiencia del refugiado está marcada por una migración forzada producto de la persecución política, la violencia generalizada, entre otros. Por ello, los refugiados no siempre poseen un proyecto migratorio ni redes sociales en el país de acogida, características que condicionan su proceso de integración social. El siguiente artículo describe y analiza el proceso de integración laboral y sociocultural de los refugiados palestinos reasentados en las ciudades de La Calera y San Felipe, V Región de Valparaíso, Chile. Entre las particularidades del caso, destaca la diferencia idiomática, cultural y religiosa que caracteriza a este grupo de familias refugiadas en relación al país de recepción.

PALABRAS CLAVE: Refugiados palestinos, integración laboral, integración sociocultural.

\begin{abstract}
The refugee experience is marked by forced migration due to political persecution and generalized violence, among other factors. As a result, refugees do not always have a migration plan or social networks in the host country, conditions that affect their social integration. The following article describes and analyzes the labor and socio-cultural integration of Palestinian refugees resettled in La Calera and San Felipe, in the Valparaíso

1 Socióloga por la Universidad de Valparaíso; diplomada en Investigación en integración de los migrantes internacionales de la Universidad de Chile. Actualmente investigadora ayudante Fondecyt en la Universidad Alberto Hurtado. Correo electrónico: karina.bijit@gmail.com
\end{abstract}


Region of Chile. Some of the salient details examined in the study are the language, culture and religious differences that characterize this group of refugee families with respect to the host country.

KEYWORDS: Palestinian refugees, labor integration, sociocultural integration.

\section{INTRODUCCIÓN}

El siguiente estudio es la exposición inicial de los resultados obtenidos de la investigación de la tesis de pregrado: "El proceso de integración sociocultural y laboral de los refugiados palestinos reasentados en las ciudades de La Calera y San Felipe, V región de Valparaíso".

Este estudio se enmarca en la llegada a Chile de un grupo de 116 refugiados palestinos provenientes del campamento de refugiados $\mathrm{Al} \mathrm{Tanf}$, ubicado en la frontera entre Siria e Irak. En Chile, las comunas destinadas para el reasentamiento de este grupo de refugiados fueron: La Calera y San Felipe, en la V Región de Valparaíso, y en las comunas de Recoleta y Nuñoa, en la Región Metropolitana (RM).

Una de las características de este caso es que este grupo de refugiados palestinos no llega por sus propios medios en busca de asilo a Chile, a diferencia de la gran mayoría de solicitantes de asilo y refugiados que viven en el país, sino que se trata más bien de una iniciativa del Alto Comisionado de las Naciones Unidas para los Refugiados (ACNUR) y el gobierno de Chile, el reasentamiento de estos refugiados. A raíz de esto ha existido una mayor preocupación hacia el proceso de integración social de este grupo. ACNUR recibió altos presupuestos para llevar a cabo este proceso. Dichos recursos fueron entregados a la Vicaría de la Pastoral Social, para que brindara apoyo y asesoría a los refugiados durante los primeros dos años de su estadía en Chile, entregándoles a cada familia una mensualidad, asesoría en la búsqueda de trabajo y vivienda, entrega de recursos para microemprendimientos laborales y clases de español.

2 Investigación que contempla entrevistas a los refugiados palestinos, a sus amistades y a los funcionarios de las tres instituciones a cargo del acompañamiento: Vicaría de la Pastoral Social, Área de Refugio del Departamento de Extranjería y Migración del Gobierno de Chile y ACNUR. Sin embargo, este artículo abordará una muestra más reducida, la cual se detalla en el apartado sobre metodología. 
Otra de las particularidades del caso estudiado la constituye las características religiosas, culturales e idiomáticas de los refugiados, así como las diferencias sociopolíticas existentes entre el país de origen y el país de acogida. El nuevo contexto de acogida genera conflictos en sus costumbres, valores, creencias y hábitos, expresados en una resistencia inicial a vincularse con la sociedad de acogida y, por ende, influyendo en su proceso de integración social en el país de reasentamiento.

Realizadas las consideraciones anteriores, el objetivo que guía este estudio es describir y analizar los elementos que inciden en el proceso de integración laboral y sociocultural de los refugiados palestinos reasentados en las ciudades de La Calera y San Felipe, V Región de Valparaíso.

\section{LAS MIGRACIONES FORZADAS}

Actualmente, un migrante puede ser definido como una persona que deja su residencia habitual, ya sea dentro de su país o con destino a otro, en búsqueda de una mejor calidad de vida y de acceso al trabajo. No obstante, en la base de la explicación de las migraciones también encontramos que existe la voluntad o decisión de las personas de desplazarse desde su lugar de origen hasta otro. En contraposición, cuando las personas se han visto forzadas a desplazarse, este hecho es más conocido como migración forzada, que suele ser producida por desastres medioambientales, violencia, guerras, persecución política, entre otras. Estas situaciones generan que este tipo de migrantes sean los de mayor vulnerabilidad y marginación.

Dentro de la categoría de migración forzada, los refugiados son el grupo más conocido. En la Convención de Ginebra de $1951^{3}$ se define al refugiado como "una persona que se encuentra fuera de su país de nacionalidad o de residencia habitual; tiene un fundado temor de persecución acerca de su raza, religión, nacionalidad, pertenencia a un determinado grupo social u opiniones políticas, y no puede o no quiere, acogerse a la protección de su país, o regresar a él, por temor a ser perseguido". Estas personas tienen derecho a protección internacional en un país de asilo; en cambio, alguien que se traslada por razones económicas, o sea para conseguir un trabajo mejor, es considerado un inmigrante y no posee los mismos beneficios (ACNUR 2007).

3 Convención sobre el estatuto de refugiados adoptada en Ginebra en 1951 por la conferencia de plenipotenciarios sobre el estatuto de los refugiados y de los apátridas, convocada por la Asamblea General de las Naciones Unidas. 
En la actualidad, el número de personas desarraigadas a la fuerza por los conflictos y la persecución en todo el mundo, asciende a 42 millones de personas. $Y$ cada año aumentan más las cifras de solicitantes de asilo y refugiados.

En Chile, según Vicaria Pastoral Social (2010), para el año 2009 había 2.728 refugiados y solicitantes de asilo, de los cuales la mayoría era de nacionalidad colombiana, otros refugiados provienen de países como Perú, Palestina, Cuba, Congo, Haití, Kenya, Ghana, entre otros.

\section{Antecedentes del refugio palestino}

La situación de los refugiados palestinos es uno de los problemas más prolongados y de mayor magnitud en la actualidad. Dicha situación se origina con la llegada de personas judías a territorio palestino tras la Primera y Segunda Guerra Mundial, impulsados por el Mandato Británico de Palestina y con la Resolución 181 de la Asamblea General de la ONU de noviembre de 1947, la cual recomendaba la división de Palestina, lo que provocó conflictos armados entre árabes y judíos, y causó la expulsión y huida de 900.000 palestinos (ACNUR 2006).

Tras estos conflictos, los refugiados palestinos migran a diversos campamentos y países del mundo árabe. A Irak llegan en tres oleadas; el primer grupo de alrededor de 5.000 personas llega tras la guerra de 1948, la segunda oleada es producto de la Guerra de los Seis Días en 1967, y por último llegan en 1991 como consecuencia de la Guerra del Golfo. Según ACNUR, en julio de 2003 había más de 22.000 refugiados palestinos en Bagdad.

En Irak, los refugiados palestinos nunca reciben el estatuto formal de refugiados, pero sí obtienen protección por parte de los sucesivos gobiernos, disfrutando de los mismos derechos que la población iraquí, accediendo a salud, educación, viviendas y otros beneficios gubernamentales.

Con la caída del régimen de Saddam Hussein en abril de 2003, los refugiados palestinos pierden los beneficios anteriores y son perseguidos por segmentos de la población iraquí y milicias armadas que los acusan de ser cercanos al antiguo régimen y de ser responsables de actos terroristas, siendo objeto de detenciones arbitrarias, despojo de sus viviendas, torturas y asesinatos (Wengert y Alfaro 2007). A raíz de esta situación, miles de refugiados palestinos huyen a tres campamentos de refugiados ubicados en la frontera entre Siria e Irak: Al-Tanf, Al-Walid y Al-Hol. 
Es en este contexto que ACNUR propone el reasentamiento de un número de refugiados palestinos provenientes del campamento Al Tanf, en Chile y Brasil, puesto que ambos países tienen programas de reasentamiento solidario.

\section{La política de refugio en Chile}

En cuanto a la política de refugio en Chile, destaca la reciente creación de una ley de protección para los refugiados, ${ }^{4}$ la Ley 20.430, dictada el 15 de abril de 2010 y reglamentada en febrero de 2011 a través del Decreto $N^{\circ} 837$. Entre los beneficios de la actual Ley de Refugio, encontramos: menor tiempo de tramitación en las solicitudes de asilo, y el abordaje de temáticas como los derechos de los refugiados, la no discriminación e integración, elementos ausentes en la Ley de Extranjería N 1.094, que regía el proceso hasta el año 2010.

En cuanto a las entidades que se hacen cargo de los solicitantes de asilo y refugiados, en el ámbito internacional encontramos al ACNUR, que desde el año 2008 posee una oficina en Chile. Su función es asesorar y apoyar al Estado chileno para que proteja y asista a la población refugiada.

Este organismo ha propiciado y patrocinado la construcción de documentos legales para la protección internacional, los cuales han sido suscritos y/o ratificados por más del 70 por ciento de los países en el mundo. Entre los documentos existentes más importantes, encontramos la Declaración de Cartagena, la Convención sobre el Estatuto de Refugiados (1951) y el Protocolo sobre el Estatuto del Refugiado (1967), siendo los dos últimos fueron suscritos por Chile durante el gobierno de Salvador Allende en 1972. En el gobierno del Presidente Patricio Aylwin (1990-1994) se incorpora a la legislación nacional aspectos regulatorios de la Convención de Refugiados de 1951. A su vez, Chile firma en el año 2004 el Programa de Reasentamiento Solidario, impulsado por el Plan de Acción de México, con el fin de mejorar la protección e integración de los refugiados que no obtuvieron protección en el primer país de asilo al cual llegan. ${ }^{5}$

En el ámbito estatal, la responsabilidad sobre la población de solicitantes de asilo y refugiados recae sobre el Departamento de Extranjería y Migración, dependiente del Ministerio del Interior, el cual crea en 2005 la Sección de Refugio y Reasentamiento. Esta

4 Hasta 2010, Chile era uno de los únicos países de Latinoamérica, junto a México, que no contaba con una ley sobre refugio.

5 A través del Programa de Reasentamiento Solidario se acogen algunos refugiados colombianos de Ecuador, los refugiados palestinos de Irak, entre otros casos. 
instancia está a cargo de tramitar las solicitudes de asilo, entregar las visas de refugio, permisos laborales y derivar a la Vicaría de la Pastoral Social (Courtis 2009).

En el ámbito de la sociedad civil, encontramos a la Vicaría de la Pastoral Social y de los Trabajadores, la cual a partir del año 2001 implementa a través del Área de Refugio, los programas de asistencia del ACNUR. Estas tres instituciones son las agencias centrales que proveen atención a los refugiados en Chile, dado su alcance, impacto y coordinación. ${ }^{6}$

\section{Revisión de los usos y perspectivas de la integración social}

Al hacer una revisión de los distintos usos y perspectivas en la literatura y sociología de las migraciones con respecto a la integración social, se pueden encontrar distintos conceptos, tales como: asimilación, aculturación, melting pot, integración, multiculturalismo o pluralismo, interculturalidad. Estos distintos modelos han sido criticados por contribuir a una ambigüedad conceptual y a confusión, pues en ocasiones un mismo término hace alusión a procesos diferentes o conceptos diferentes hacen alusión a un mismo proceso; inclusive encontramos conceptos que engloban a otros como si fuesen subprocesos, entre otras situaciones (Blanco 2002). A continuación se describirán brevemente algunos de estos modelos.

Desde el siglo XIX, el fenómeno migratorio ha sido abordado por países caracterizados por ser centros de atracción migratoria, como Estados Unidos y Francia. En Estados Unidos, la Escuela de Chicago aborda el fenómeno migratorio y su asentamiento en las ciudades a raíz del proceso de industrialización y crecimiento urbano, destacándose los trabajos de Thomas y Znaniecki, con "El campesino polaco en Europa y América", introduciendo el concepto de asimilación, retomado posteriormente por Park (Solé et al. 2002), el cual describe la inserción de los inmigrantes como un ciclo de relaciones étnicas, con cuatro fases: rivalidad, conflicto, adaptación y asimilación. La asimilación es "el proceso mediante el cual una persona o grupo de personas adopta como propia la cultura dominante en la sociedad, al mismo tiempo que va abandonando su identidad cultural diferenciada" (Torres 2005:2).

De forma similar, el Modelo Republicano Francés implica la adopción de la lengua y cultura francesas, siendo por lo tanto la aculturación el proceso que deviene en el éxito de la integración de los inmigrantes en la sociedad francesa, modelo que se mantiene

6 Existen otras instituciones de la sociedad civil, principalmente del ámbito religioso y académico, que poseen programas focalizados hacia la población migrante y refugiada; sin embargo, estas no serán abordadas en este estudio dado el bajo alcance que ellas poseen en relación a los refugiados palestinos. 
hasta la década de 1980, cuando surgen las primeras movilizaciones de los hijos de inmigrantes frente a las problemáticas sociales que generaba dicho modelo.

En general, a partir de la década de 1960 se empezó a cuestionar el modelo asimilacionista, en donde Gordon, exponente de la Escuela de Chicago, critica a Park por confundir integración con asimilación (Solé et al. 2002). Otros motivos de la pérdida de legitimidad del modelo son las exigencias sociales de los grupos minoritarios, así como las dificultades y problemas de la inserción social de los inmigrantes. Dando paso al pluralismo cultural $^{7} \mathrm{o}$ al multiculturalismo, el cual tuvo diversas expresiones según el país desde el cual se analice, básicamente reconocía la diversidad cultural, la coexistencia de distintos grupos en un mismo espacio, pero viviendo separados sin mezclarse. Es por ello que estos modelos son criticados, pues debilitan la integración y cohesión social, exaltando la fragmentación.

Actualmente, diversos autores abordan la problemática de la integración social de los inmigrantes, los cuales rescatan algunas ideas de enfoques precedentes, en conjunto con otras propuestas, entre las cuales nos parece útil considerar aquellas que reconocen la complejidad y multidimensionalidad del fenómeno, afectado por múltiples factores: sociales, jurídicos, económicos, políticos, religiosos, psicológicos, temporales, entre otros, los cuales inciden en mayor o menor medida según el caso abordado (Giménez 2002). Identificamos factores externos a los inmigrantes tales como marco jurídico, mercado laboral, condiciones políticas y actitud de la sociedad de acogida y factores internos (centrales en esta investigación), tales como cualificación profesional, disposición de los sujetos a interactuar con su entorno social, construcción de redes de solidaridad, aprendizaje del idioma y mejora en sus condiciones de vida, entre otros.

Otro aspecto útil de considerar en el análisis de la integración social, es que no existe una integración plena, sino más bien aspectos en los cuales se logra una mayor o menor integración, según la dimensión que se aborde (Gualda 2001). Para el caso de este estudio, son la dimensión laboral y la sociocultural, los ámbitos a abordar. En particular se toman como referencia para esta investigación las propuestas respecto de la integración social de Solé y Blanco, quienes se complementan e interrelacionan en distintos aspectos.

Solé, a partir de su estudio sobre las migraciones en Cataluña, construye el concepto de integración sociocultural, la cual se aleja de los postulados de la asimilación de

7 Gordon fue uno de los mayores exponentes del pluralismo cultural, quien entiende por integración la incorporación igualitaria de los inmigrantes a la política y la estructura socioeconómica de la comunidad, vale decir, una incorporación ausente de discriminación, por lo cual no se produce aculturación, pero sí asimilación estructural (Blanco 1990). 
la lengua y de los rasgos culturales predominantes, definiendo la integración como "la interpenetración de los miembros y elementos culturales de dos poblaciones en una única y nueva estructura social y cultural" (Solé et al. 2002:21). Establece dos niveles de integración: integración estructural e integración sociocultural. La primera hace alusión a la integración ocupacional y social a través de la inserción en una determinada clase social. La segunda se expresa en la voluntad de los inmigrantes en reivindicar como propio el ámbito en el cual se sientan ciudadanos de derechos, así como coprotagonistas de un proyecto político (Solé et al. 2002). Comprendiéndose la integración desde cuatro subprocesos: amoldarse al tipo y condiciones del trabajo (integración ocupacional), adaptarse a las condiciones de vida urbanas (integración urbana), la aceptación progresiva y voluntaria de las instituciones sociales y políticas a través de la participación (integración política) y la adopción voluntaria de las normas, costumbres y lengua de la sociedad receptora (integración sociocultural) (Solé et al. 2002).

No obstante, Blanco (1993, cit. en Solé et al. 2002) señala que "la incorporación del inmigrante a la estructura productiva (integración estructural) no tiene por qué conllevar necesariamente ni de forma simultánea, una participación efectiva en las instituciones y organizaciones sociales mayoritarias ni el establecimiento de relaciones primarias con la población autóctona" (Blanco 1993:327, cit. en Solé et al. 2002:22).

Con respecto a la integración cultural, Blanco agrega que la incorporación por parte de los inmigrantes de los hábitos culturales de la sociedad de acogida tampoco tiene que significar la adopción de una identidad étnica, cultural o nacional, por lo cual la autora agrega la identidad colectiva, distinguiendo entonces las siguientes dimensiones: la estructural, que comprende la incorporación a la estructura productiva, las relaciones sociales y participación en organizaciones; la dimensión cultural y la identidad colectiva, entendida esta última como el sentimiento de pertenencia, en donde los grupos se reconocen a sí mismos y forman parte de una misma comunidad (Blanco 1993, cit. en Solé et al. 2002).

Finalmente, cabe señalar en relación a las distintas fases de la integración social anteriormente esbozadas, que en la práctica estas etapas no encajan o explican de manera perfecta el fenómeno; de alguna u otra forma se dan combinaciones de dichas fases de integración, ocurriendo algunas de forma paralela e incompletas, retrocediendo o avanzando en la jerarquía de la integración según la perspectiva de los sujetos desde los cuales se analice el fenómeno. 


\section{MATERIALES Y MÉTODOS}

Esta investigación tiene un diseño cualitativo, no experimental y semiemergente. El tipo de estudio es descriptivo. En cuanto al universo y la muestra, el universo lo conforman los refugiados palestinos en Chile y la muestra son los refugiados reasentados en las ciudades de La Calera y San Felipe. La unidad muestral la conforman los hombres y mujeres mayores de 18 años, sean solteros o casados, siendo estos los criterios de selección de los sujetos, junto con la accesibilidad de los mismos.

Para efectos de este artículo se abordan los resultados obtenidos de todas las entrevistas de los refugiados de La Calera y la mitad de las entrevistas realizadas a los refugiados de San Felipe. Esto suma en total 11 entrevistas correspondientes a cuatro familias reasentadas en La Calera y a tres de las seis familias entrevistadas en San Felipe, además de un refugiado soltero residente en la última ciudad.

\section{Cuadro $\mathrm{N}^{\circ} 1$}

Muestra de entrevistas semiestructuradas a refugiados palestinos

\begin{tabular}{|c|c|c|c|c|c|}
\hline Sexo & Edad & $\begin{array}{l}\text { Estado } \\
\text { Civil }\end{array}$ & $\begin{array}{l}\text { Comuna } \\
\text { Residencia }\end{array}$ & $\begin{array}{l}\text { Modalidad de la } \\
\text { entrevista }\end{array}$ & $\begin{array}{c}\text { Conforman } \\
\text { núcleo familiar }\end{array}$ \\
\hline Mujer & 41 años & Casada & La Calera & Individual & \multirow{2}{*}{ Sí } \\
\hline Hombre & 39 años & Casado & La Calera & Individual & \\
\hline Mujer & 32 años & Casada & La Calera & Individual & \multirow{2}{*}{ Sí } \\
\hline Hombre & 36 años & Casado & La Calera & Individual & \\
\hline Mujer & 36 años & Casada & La Calera & Individual & Sí \\
\hline Hombre & 46 años & Casado & La Calera & Con su cónyugue & \multirow{2}{*}{ Sí } \\
\hline Mujer & 39 años & Casada & La Calera & Con su cónyugue & \\
\hline Hombre & 51 años & Casado & San Felipe & Con su cónyugue & \multirow{2}{*}{ Sí } \\
\hline Mujer & 49 años & Casada & San Felipe & Con su cónyugue & \\
\hline Hombre & 43 años & Casado & San Felipe & Con su cónyugue & \multirow{2}{*}{ Sí } \\
\hline Mujer & 40 años & Casada & San Felipe & Con su cónyugue & \\
\hline Hombre & 29 años & Casado & San Felipe & individual & \multirow{2}{*}{ Sí } \\
\hline Mujer & 29 años & Casada & San Felipe & Individual & \\
\hline Hombre & 33 años & Soltero & San Felipe & Individual & No \\
\hline
\end{tabular}


Como se aprecia en la tabla expuesta, en algunos casos se entrevisto de forma individual al hombre y posteriormente a la mujer, miembros del mismo núcleo familiar, mientras que solo en uno de los caso se logra entrevistar a la mujer y en el resto de las entrevistas ambos cónyuges estaban presentes en la conversación.

También es necesario señalar que en dos entrevistas realizadas a ambos conyugues en San Felipe, los hijos ayudaron a traducir las preguntas de las entrevistas y las respuestas de sus padres. En uno de los casos, participó un hijo de 16 años y en el segundo caso, participó un hijo de 17 años.

\section{Cuadro $\mathrm{N}^{\circ} 2$}

Muestra del número de familias y cónyuges entrevistados según sexo y ciudad de residencia

\begin{tabular}{|c|c|c|c|}
\hline $\begin{array}{c}\text { Número de } \\
\text { identificación de } \\
\text { las familias }\end{array}$ & Hombre & Mujer & \multirow{2}{*}{ Ciudad } \\
\cline { 1 - 3 } Familia 1 & $\mathrm{x}$ & $\mathrm{x}$ & \multirow{2}{*}{ La Calera } \\
\hline Familia 2 & $\mathrm{x}$ & $\mathrm{x}$ & \multirow{2}{*}{ San Felipe } \\
\hline Familia 3 & $\mathrm{x}$ & $\mathrm{x}$ & \\
\hline Familia 4 & 0 & $\mathrm{x}$ & $\mathrm{x}$ \\
\hline Familia 5 & $\mathrm{x}$ & 0 & \\
\hline Familia 6 & $\mathrm{x}$ & $\mathrm{x}$ & \\
\hline Familia 7 & $\mathrm{x}$ &
\end{tabular}

Respecto del estado civil, la mayoría de los refugiados de La Calera y San Felipe son casados. Poseen una composición familiar nuclear biparental, en donde el género del jefe de hogar es masculino. En cuanto a la estructura familiar (según el Programa Puente), todas las familias son adultas, pues sus edades fluctúan entre los 25 y 59 años de edad. Las diferencias existentes entre las familias de La Calera y San Felipe se dan básicamente en cuanto al promedio de hijos por hogar, pues en La Calera el promedio de hijos es de cuatro, mientras que en San Felipe es de tres.

Es importante mencionar que hay pocos refugiados solteros (en total son cuatro): en San Felipe viven tres y en La Calera uno, siendo todos hombres. Solo uno de ellos llegó a Chile sin estar vinculado familiarmente a otras personas del grupo de refugiados, sien- 
do el caso de un soltero residente en San Felipe, quien fue entrevistado y se contempla en los resultados de esta investigación.

Por otro lado, una segunda muestra estuvo constituida por las instituciones que asesoraron el proceso de integración de los refugiados, específicamente por funcionarios de la Vicaría de la Pastoral Social y de los trabajadores. El criterio de selección fue intencionado, pues los sujetos eran informantes estratégicos. En el análisis de los datos de las entrevistas se incluyen dos coordinadores locales, un asesor laboral y un intérprete.

Las técnicas de producción de datos utilizados para esta investigación fueron la entrevista semiestructurada utilizada con los refugiados palestinos, y la entrevista a informantes claves, aplicada a funcionarios de la Vicaría de la Pastoral Social y de los Trabajadores.

Los datos arrojados por las entrevistas fueron abordados a través del análisis de contenido, permitiendo resumir los temas en categorías analíticas y códigos que facilitaron la descripción y comparación de los fenómenos analizados.

\section{EL PROCESO DE INTEGRACIÓN LABORAL Y SOCIOCULTURAL}

\section{Las implicaciones del desplazamiento en la vida de los refugiados}

Un aspecto fundamental del proceso de integración de los refugiados palestinos en Chile, es la comprensión de las implicancias del desplazamiento (o migración forzada) en la vida de los sujetos. Bello señala que:

...ser desplazado significa haber perdido su lugar, dejar de ser y estar en el lugar en que se ha sido; ser desplazado es sinónimo de incertidumbre, desarraigo, anonimato, dolor, rabia, presencia terca y obstinada del recuerdo y esfuerzo de olvido. (2001:8)

Antes del desplazamiento y en medio de la guerra, los refugiados palestinos enfrentaron situaciones violentas y degradantes, en un ambiente de desprotección. En la mayoría de los casos estas situaciones obligaron a las personas a tomar la decisión de salir del país o región. Tal como se aprecia en la siguiente cita, al preguntarle a una familia por las condiciones de vida en Irak durante la guerra, la situación era la siguiente:

...mataban a mucha gente y en la puerta de mi casa pusieron una bomba, explotó y por eso salimos. Mi mamá después de que pasó la bomba estuvo en el hospital como 
un mes y después de eso nosotros salimos; algunos familiares también salieron, otros se quedaron en Irak. (Hijo, 17 años)

La mayoría de las personas entrevistadas señala múltiples historias respecto de la violencia y persecución que vivieron en Irak, desde hijos secuestrados, familiares encarcelados, torturados o asesinados, etc. Son estos eventos los que determinan su salida del país, situación que impacta en las familias y comunidades, fragmentándolas.

Posteriormente, en el campamento de refugiados Al Tanf, la larga estadía y las precarias condiciones de vida, los lleva a aceptar el ofrecimiento de migrar a Chile; sin embargo, la mayoría de los entrevistados señala que esta decisión también fue una obligación, pues en el momento no había otra opción: Chile fue el primer país que aceptó reasentar a refugiados palestinos provenientes de Irak.

A modo de ejemplo respecto de la pregunta “¿Qué lo motivó a venir a Chile?”, un entrevistado responde:

...estaba obligado, por estar dos años en el campamento no tuvimos otra solución, solamente Chile. Pregunté por Chile; nos dijeron que es un país pobre, pero no habíamos imaginado que el país era tan pobre. Intentamos rechazar eso, nos dijeron: si rechazan no tendrán más soluciones, no hay salida, estábamos obligados a salir. (Hombre casado, 39 años)

Dicha obligación se presenta como un elemento fundamental para entender las motivaciones y la disposición personal de los sujetos que se ven sometidos a una migración forzada y que deben asentarse en un contexto social en el cual no poseían proyecciones ni intereses.

A dicha obligación se agrega el desconocimiento sobre el país de reasentamiento. Muchos entrevistados señalan no haber escuchado en su vida hablar de Chile, no saber dónde quedaba en el mapa, que idioma se hablaba ni cómo se vivía en el país. La única referencia que tienen de Chile la obtienen cuando delegados del Departamento de Extranjería y Migración del Gobierno de Chile, junto a funcionarios de la Vicaría de la Pastoral Social y de los Trabajadores, viajan al campamento a ofrecer reasentamiento a un grupo de refugiados, explicándoles a través de charlas y entrevistas, cómo era la vida en el país. Esta información generó diversas expectativas de la vida en Chile, generando en ocasiones imaginarios lejanos a la realidad. Tal como se aprecia en la siguiente cita: "me imaginé que voy a vivir como el nivel de la mejor familia de aquí, y resultó el peor" (Mujer casada, 32 años). 


\section{La llegada a Chile}

Al llegar a Chile, los refugiados pasan de una situación de malestar, inseguridad y temor en el país de origen, en el campamento de refugiados, a un estado de frustración en el país de reasentamiento, producto de las expectativas generadas en el campamento y de la no concreción de las mismas en Chile. Múltiples críticas se expresan hacia la labor de la Vicaría y se compara constantemente la situación en Chile con la de otros refugiados que con posterioridad salen del campamento a países europeos. La siguiente cita es elocuente:

¿Por qué nos trajeron aquí, sabiendo que su país es pobre? [...] ¿Por qué no nos llevaron a Canadá, Suecia o Noruega? Nuestra gente en el campamento, todos salieron a países europeos; estamos escuchando sus noticias, todos tienen buena situación y más que buena situación, no solamente en lo material en dinero, también en estudios de los niños, en todos los aspectos mejor que nosotros. (Hombre casado, 36 años)

El relato de esta familia grafica el malestar de los refugiados frente a las condiciones de vida inesperadas y los múltiples cambios que se ven obligados a enfrentar durante el proceso de ubicación e inserción en Chile, situación por la cual responsabilizan a las entidades que gestionaron el proceso de reasentamiento.

Con respecto a la percepción que tienen del país de acogida, se visibilizan por un lado aspectos tales como la libertad, seguridad y tranquilidad de la vida en Chile, versus la frustración que les produce la falta de trabajos que se ajusten a sus expectativas, así como el precario nivel de ingreso y las condiciones de vida en general.

Yo vivo en seguridad en Chile, estamos tranquilos, pero no hay trabajo; sin trabajo no puedo sobrevivir [...] Si encuentro un trabajo de 300.000 yo y mi señora, se soluciona nuestro problema. (Hombre casado, 46 años)

Todas las familias aquí son de sies personas, no son como las familias chilenas de dos personas, necesitamos ropa, necesitamos tratamiento, no puedo comprar lo del colegio, no puedo comprar cuadernos ni lápices. (Mujer casada, 39 años)

Bello señala que "la urgencia de las necesidades económicas parecen no dejar tiempo ni espacio para afrontar la grave situación emocional por la que atraviesan todos los miembros de la familia" (2001:22), al punto de que el conflicto emocional aparece intermitente y no central en el discurso, como se aprecia en relación al comentario que la 
entrevistada hace con respecto a que "necesita tratamiento", refiriéndose a la situación de estrés en la cual se encuentra (rascando su piel constantemente).

Siguiendo con la situación de las familias al llegar a Chile, destacan en su relato respecto de la llegada, las múltiples diferencias entre el país de acogida y su país de origen antes de la guerra. Por un lado resaltan las situaciones relacionadas con el trabajo y las condiciones económicas, y por otro, las diferencias culturales con las que se encuentran en el país de acogida. Así se observa en la siguiente cita:

Diferente mucho entre Chile e Irak. Por ejemplo el trabajo, dice mi papá, porque hay más problemas, allá teníamos plata, allá no nos importa la plata, nos importa la gente, cómo vive, pero no importa la plata porque todos tienen plata, pero aquí el problema es que no hay plata, esa es la diferencia. (Hijo, 16 años)

El desplazamiento desestructura mundos sociales y simbólicos provocando una crisis o ruptura de los valores, las prácticas, las formas y estilos de vida. Obliga a las personas refugiadas a enfrentarse a ambientes desconocidos y a asumir nuevas actitudes y actividades en condiciones emocionales difíciles (Bello 2001).

\section{Elementos presentes en el proceso de integración laboral}

En cuanto a su trayectoria laboral, al preguntarles por sus trabajos en el país de origen, la mayoría de los hombres declara haber realizado trabajos de poca cualificación laboral. En su mayoría poseen oficios aprendidos, como mecánicos de autos y manejo de maquinarias relacionadas con la extracción de petróleo; el resto se empleaba en el sector servicios o comercio, como independientes o dependientes; muy pocos señalan contar con estudios, siendo en el caso de los hombres las profesiones que más se repiten: pedagogía en lengua árabe e historia. En el caso de las mujeres, la mayoría no trabajaba en Irak; solo una de ellas señala haberse desempeñado como contadora y otra como orfebre previamente al matrimonio.

Al llegar a Chile e insertarse laboralmente, muchos refugiados han terminado trabajando en actividades que no se relacionan con los trabajos que realizaban en el país de origen; inclusive aquellos que cuentan con profesiones $u$ oficios no han podido continuar desempeñándolos, y señalan en sus relatos el haber sufrido una movilidad descendente en sus condiciones de vida. Como se aprecia en la siguiente cita: "No es mi trabajo el restorán, mi oficio es soldador de tubos de petróleo; muy poca gente maneja ese trabajo aquí en Chile. Perdí mi oficio y convertí un oficio bueno a vendedor de dulces". (Hombre casado, 39 años) 
También destaca la dificultad inicial de los refugiados palestinos para encontrar un trabajo estable que responda a sus habilidades (en su mayoría oficios aprendidos), así como a sus altas expectativas laborales y sus dificultades idiomáticas, situaciones que complejizan el proceso de integración laboral.

Dicha situación se expresa en su gran inestabilidad laboral, la que los vuelve muy dependientes del subsidio entregado por ACNUR a través de la Vicaría, dinero del cual dependen los primeros dos años de su estancia en Chile, y que en la mayoría de los casos es una suma mayor que el ingreso que obtienen de los trabajos a los cuales pueden acceder. Como lo ejemplifica la siguiente cita:

Imaginaba que los países occidentales son más avanzados, tienen más trabajos y mejor sueldo, me prometieron subsidio de 800 dólares, imaginaba que voy a trabajar, me hicieron imaginar que en Chile el sueldo más que el subsidio, al llegar encontré que la situación es al contrario, el trabajo más o menos la mitad del subsidio, y me sorprendió eso. (Hombre casado, 36 años)

Sin duda, un aspecto que influye en el proceso de integración es la diferencia existente entre las condiciones de trabajo del mercado laboral de origen y el de destino. En Chile, la cualificación laboral y especialización se vuelven fundamentales para acceder a una mejor remuneración. A su vez, los subsidios que entrega el Estado son menores en relación a los otorgados en Irak; por ello, en relación a los relatos de los entrevistados, independientemente del ingreso que se tuviera, las condiciones materiales básicas se encontraban resueltas. Así se aprecia en la siguiente cita:

Saddam Hussein ayuda mucho a los palestinos. Yaser Arafat: él le paso plata a Saddam Husein para que nosotros vivir allá; a los palestinos regaló casa, agua gratuita, gas, no compramos azúcar, leche, aceite, detergente, jabón. (Mujer casada, 41 años)

La percepción que prácticamente todos los refugiados tienen de Chile, en relación al trabajo, el ingreso y las condiciones materiales de vida, es negativa en relación a su país de origen antes de la guerra: "El trabajo en Irak da sueldo bueno para vivir y sobra, no es como aquí, el mes de trabajo no da para diez días”. (Mujer casada, 41 años)

La precariedad del ingreso al cual pueden acceder los refugiados, resulta recurrente en el discurso, en el cual resalta "el valor simbólico que le otorgan al dinero" en relación con los numerosos gastos que sus familias generan (Soriano 2006). Según fuentes de la Vicaría, los refugiados palestinos reciben un ingreso que va desde los $150.000 \mathrm{mil}$ a los 
300.000 mil pesos mensuales por familia, (Vicaría de la Pastoral Social y de los Trabajadores 2010) situación que los mantiene fluctuando al borde de la línea de pobreza, pues el número promedio de integrantes por hogar es de seis personas.

\section{Trabajadores dependientes e independientes}

Los refugiados que se emplean como asalariados se insertan en trabajos caracterizados por sus precarias condiciones laborales, ya sean de contratación temporal, en horarios nocturnos y de baja remuneración, en sectores como construcción, agricultura, comercio e industria alimentaria.

Esta situación los lleva a dejar dichos trabajos al poco tiempo de haberse incorporado a las labores, esperando encontrar trabajos mejor remunerados o que ofrezcan mayor flexibilidad horaria. Los distintos ritmos a los cuales estaban acostumbrados es otro factor que influye en la inestabilidad laboral que presentan los entrevistados, situación que se relaciona principalmente con los horarios y permisos, mucho más flexibles en Irak y acordes a su religión. Según los relatos, dicha flexibilidad está asociada a permisos para rezar en horarios de trabajo ${ }^{8}$ y a la celebración de fiestas religiosas como Ramadán, en donde se ayuna durante un mes. Estas facilidades no se encuentran en los trabajos a los que acceden en Chile. Se trata de una situación que con el tiempo han tenido que asumir, relegando dichas prácticas al mundo privado del hogar.

Por otro lado, aquellos que han optado por iniciar trabajos por cuenta propia, a través de emprendimientos vinculados a la venta de comida y dulces árabes, contaron con un subsidio para microemprendimiento gestionado por la Vicaría, de un millón de pesos para los hombres y setecientos mil pesos para las mujeres, subsidio que estuvo disponible al segundo año de su estadía en Chile, por lo que dichas familias también tuvieron experiencias de trabajos como dependientes, combinadas con largos periodos de cesantía y venta informal de dulces árabes, en la calle o barrio en el cual residían.

Aquellos que empezaron microemprendimientos también encontraron dificultades a la hora de gestionar los proyectos, producto del desconocimiento por parte de los refugiados de las normas y trámites que implica levantar un local comercial; sin embargo, gracias a la asesoría de la Vicaría y a las amistades con las que contaban algunos refu-

8 Funcionarios de la Vicaría señalan que algunos de los refugiados renunciaron o fueron despedidos por negárseles la práctica de rezar en el horario de trabajo. 
giados, pudieron salir adelante. Siendo en este punto muy significativo el rol de las redes sociales y amistades de las familias en el éxito de los microemprendimientos laborales.

Así encontramos que aquellas familias que contaban con redes sociales con fuerte capital social y económico ${ }^{9}$ tuvieron mayor facilidad para montar sus locales, equiparlos y mantenerlos en el tiempo, en comparación con aquellos que no poseían redes sociales o cuyas redes no contaban con el mismo capital social y económico.

Otra característica de estos refugiados y familias que han tenido éxito con sus locales comerciales, es su disposición hacia la sociedad de acogida. En sus relatos señalan tener muchos amigos, estar a gusto en Chile y se observa en ellos una relación de pareja más solida e igualitaria en relación a los demás entrevistados.

Volviendo al tema de las redes sociales, sin duda es fundamental su estudio para la comprensión de las migraciones contemporáneas y los procesos de integración en las sociedades de acogida, Thomas y Znaniecki señalan que:

...miembros de las redes sociales de pertenencia ya sean integrantes de la red de origen que conservan algún tipo de relación de ayuda con el sujeto desplazado, ya sean los nuevos vínculos que se establecen en la comunidad de acogida, son el conjunto de recursos humanos no formalizados en los que el inmigrante confía para obtener algún tipo de ayuda encaminada a la provisión de la satisfacción de sus necesidades. (Martínez 1996, cit. en Soriano 2006:183).

En sociología de las migraciones, las teorías existentes con respecto a las redes de apoyo y reciprocidad se dividen en: endógenas (conformadas por relaciones entre los miembros de un mismo colectivo inmigrante) o exógenas (relaciones con otros sujetos, fuera del grupo de pertenencia). En el caso de las redes de apoyo de los refugiados palestinos, estas son eminentemente exógenas, dado que los refugiados llegan a Chile en las mismas fechas y no existe de manera previa generaciones de refugiados palestinos que cuenten con una cierta experiencia respecto del proceso de inserción en la sociedad de acogida. ${ }^{10}$

9 Según Bourdieu (1999), el capital económico está compuesto por los recursos y propiedades materiales, así como por activos financieros. El capital social está constituido por los diversos tipos de redes personales y contactos a los cuales pueden acceder los sujetos.

10 La comunidad de palestinos existente en Chile llega entre 1905 y 1914 (Agar y Saffie 2005). En la actualidad encontramos a las cuartas o quintas generaciones de descendientes palestinos que han perdido, en la mayoría de los casos, su idioma de origen y han transformado su identidad cultural. 
Estas redes de apoyo se enmarcan en distintos espacios sociales tales como: el barrio, el espacio laboral, los vínculos con las comunidades musulmanas y de descendientes palestinos en Chile. Entre las formas que estas redes de apoyo han ayudado en el ámbito laboral a los refugiados, encontramos desde acompañamiento en trámites cotidianos, contactos laborales, hasta ayuda económica.

Como ejemplo, al preguntarle a un refugiado si alguien lo ayudó a iniciar su local de comida y dulces árabes, este señala:

...el padrino mío, él me prestó dinero y otro amigo me encontró el negocio para mí y él me dijo: "hay tal negocio". Yo hablé con el dueño del negocio. Él "mi amigo" es también mi aval; si yo no pago y me atraso, él paga... es mi vecino. (Hombre casado, 29 años)

Estas amistades provienen de espacios sociales definidos. Una de ellas pertenece a la comunidad de descendientes palestinos en Chile y la otra amistad que el entrevistado menciona es de origen chileno, cuyo espacio en común es el barrio en que trabajan, pues la consulta del dentista se encuentra junto al local de comida árabe del entrevistado. Ambas amistades han apoyado económicamente a esta familia palestina, situación que sin duda responde a la condición socioeconómica acomodada de dichos sujetos, motivo que les permite realizar este tipo de ayuda.

Otro tipo de red de apoyo lo constituyen amistades en el barrio, pero que responden a condiciones económicas similares a los refugiados y por ende no cuentan con capital económico, sin embargo su apoyo se concreta en términos emocionales y cotidianos, como puede ser el compartir con la familia, acompañarlos al consultorio de salud, ayudarlos con el idioma y asesorarlos en trámites de diversa índole.

El nuevo contexto del país de acogida exige además que tanto el hombre como la mujer trabajen en distintos espacios laborales, situación difícil de aceptar para las familias palestinas de religión musulmana, producto de la clara delimitación y distribución de los roles en las sociedades islámicas, en donde es el hombre quien sale de la casa en búsqueda del sustento familiar, mientras que a la mujer se le educa desde la infancia para cumplir la función de esposa y madre, inculcándole valores que norman su vida, tales como docilidad, obediencia, matrimonio y procreación (Soriano y Santos 2002). Por ello, se alteran los proyectos de vida en términos de los roles de género que los miembros de la familia estaban acostumbrados a cumplir, situación que se grafica en el siguiente relato: 
...yo sé que mi marido solo él trabaja, yo, ama de casa, ayudar a mis niños [...], hace el almuerzo, todas las cosas en la casa, [...] pero mucho trabajo, antes de estos años yo muy joven, ahora muy vieja por el trabajo; antes la ropa, la casa, ahora igual a hombre, sucias nosotras, ahí trabajando. ${ }^{11}$ (Mujer casada, 41 años)

Esta modificación en los roles de la pareja incide también en los tradicionales esquemas de poder y autoridad, los cuales se ven alterados (Bello 2001).

En Irak la mujer para la casa, con los niños, para comer, todas las cosas en la casa nomás, los hombres trabajar. La mujer pone pierna sobre pierna y si vuelve marido sin dinero, le pone la chala en la cabeza [risas]. En Chile se cambió mucho, en Irak cuando el hombre pide algo tiene su palabra, en Chile cambió, ahora no puedo tomar una decisión solo, si tomo una decisión solo aquí en este país, la mujer echa al hombre de la casa y le avisa a carabineros [risas]. (Hombre casado, 39 años)

Otro impacto sobre los roles de los miembros de la familia lo sufren los hijos, quienes pasan a ocupar un papel central en cuanto al idioma, producto del rápido aprendizaje que adquieren del mismo. En algunos casos, esta ventaja idiomática de los hijos les juega en contra, en tanto sus padres dependen excesivamente de ellos para que traduzcan situaciones o para que los ayuden a realizar trámites, existiendo casos extremos, como el que relata la coordinadora local del Programa de Reasentamiento Humanitario de La Calera: "el caso de un padre, que llevó a su niño de 11 años a su pega para que él pueda explicar lo que le están diciendo, por el idioma y el niño quiere ir al colegio, quiere tener sus amigos".

Por otro lado, los hijos también adquieren mayor autonomía en relación a sus padres; dicha autonomía se da principalmente vinculada a la facilidad que tienen para conversar, hacer amigos y moverse por la ciudad.

Otra consecuencia que se repite en los relatos, producto del desplazamiento, es la fragmentación de las familias. Los distintos integrantes salen a otros países de reasentamiento o se quedan en el país de origen. Como señala una entrevistada: "Allá en Irak teníamos tíos, abuelos, hermanos, familiares míos y de (mi esposo), pero aquí no tenemos a nadie". (Mujer casada, 39 años)

Este relato ilustra además la carencia de una red de solidaridad más cercana, en términos de pertenencia, con la que no se cuenta en el país de acogida.

11 La mujer del relato se encontraba preparando el pan en su local de comida árabe, antes de ser entrevistada. 


\section{Elementos presentes en el proceso de integración sociocultural}

La comprensión de los códigos culturales lejanos a los propios es una tarea compleja, por ello situar a la cultura de origen de los sujetos investigados nos permite comprender mejor cómo se desarrolla su proceso de integración social en la sociedad de acogida (Soriano y Santos 2002).

Respecto de lo mismo, Ariño (1998) señala que "no es posible explicar el comportamiento humano sin tener en cuenta que los actores sociales son agentes productores de significado, usuarios de símbolos, narradores de historias con las que producen significado e identidad" (cit. en Soriano y Santos 2002:172).

Por ello, las diferencias culturales existentes entre los países de origen y de acogida afectan el proceso de integración de las personas: aquellos procedentes de sociedades más cercanas culturalmente poseen mayores facilidades de integración (Smith y Bond 1990, cit. en Basabe, Zlobina y Páez 2004). Al contrario sucede con aquellos que provienen de sociedades más distantes, siendo por ejemplo el idioma uno de los aspectos que facilita u obstaculiza dicho proceso.

En relación a estas reflexiones, es interesante señalar una situación que se dio en el trabajo de campo, donde el intérprete de la Vicaría, en medio de la traducción de una de las entrevistas, criticó a los refugiados palestinos por no aceptar los trabajos que se les ofrecían y los comparó con los refugiados colombianos que llegan a Chile y aceptan cualquier trabajo. Frente a este comentario, un refugiado dio por respuesta lo siguiente:

La diferencia entre nosotros y los colombianos: costumbres. Tienen las mismas costumbres y tradición de la familia chilena, el idioma el mismo, cuando se cambian de un país a otro no tienen diferencia, un país mejor que su propio país, diferencia grande entre nosotros y los colombianos. (Hombre casado, 36 años)

Sin duda, la relación existente entre sociedad y religión es lo que marca las diferencias entre el país de origen y el de acogida, siendo uno de los primeros choques a los cuales se enfrentan los musulmanes al llegar a una sociedad occidental, la secularización del Estado y la sociedad (Soriano y Santos 2002). Pues

El Islam no solo organiza la vida espiritual sino que reglamenta también la vida social, política y económica... transmite un modo de representar, organizar y explicar 
el mundo que lo rodea, por lo que condiciona tanto el comportamiento interpersonal como la organización social, las normas, costumbres, etc. (Soriano y Santos 2002:175)

En cuanto a las diferencias entre la cultura de acogida y la de origen, los refugiados en general concuerdan con el rechazo hacia ciertas costumbres que en su religión son consideradas pecado, tales como la poca vestimenta en el caso de las mujeres, el consumo de alcohol y drogas, las relaciones de pareja fuera del matrimonio, los valores inculcados en la educación de los hijos, entre otros. Resaltan también los aspectos que para algunos generan gran rechazo mientras que para otros son más bien aceptados, o considerados normales al transcurrir el tiempo de su estadía en Chile. Así se desprende de las siguientes citas con respecto a las diferencias entre Chile e Irak:

Es como la diferencia entre la tierra y el cielo, lo más simple, las costumbres, la cultura, la religión, sus vestidos, su estilo de vida, su saludo mujer a hombre, hombre a mujer, no nos gusta, niñas chiquititas hacen amistades, fuman, toman, invitan a sus amigos a su casa, van unos a la casa del otro, todo eso no es nuestro. (Mujer casada, 32 años)

Soy libre en este país, puedo hacer cualquier cosa; en Irak no puedo hacer nada, no sé, cualquier cosa, pueda saludar a la mujer, es más fácil conversar con una mujer, en Irak te acusan, o castigan, no se puede. (Hombre casado, 39 años)

Los refugiados palestinos con familia siguen manteniendo las prácticas culturales y tradiciones de su país de origen, en especial en los espacios privados, donde las costumbres, prácticas religiosas, gastronomía e idioma son reproducidos y transmitidos a los hijos. Es por ello que no ha existido un proceso de asimilación o fusión de culturas, al no existir para los refugiados una identificación con las costumbres del país de acogida, ni una obligación de la adopción de las mismas para evitar la exclusión en la sociedad de reasentamiento. Por lo demás, el escaso tiempo transcurrido (tres años desde su llegada) tampoco ha permitido, por el momento, una mayor interiorización de las costumbres del país de acogida por parte de los niños, niñas y adolecentes del grupo, cuya edad promedio es de 9 años, siendo aún muy dependientes de sus padres.

Frente a la situación de los hijos, las familias coinciden en su preocupación y temor a que estos pierdan su cultura; es por esto que se repite en el discurso la necesidad de mantener sus tradiciones y la transmisión de valores a través de la enseñanza a los hijos, visibilizándose en los relatos el rol de la mujer en la familia, como encargada de mantener las costumbres del país de origen. Así se aprecia en la siguiente cita: 
Enseño a mis hijos cada día lo que es bueno y malo, qué es lo que aceptamos de nuestra cultura, qué es lo que corresponde a nuestra cultura, para que vean si lo hacen o no lo hacen, antes de salir les recomiendo a ellos. Los amigos de (su hijo) si quieren demostrar alguna cosa que no es de nuestra cultura le oriento a ellos para que lo rechacen. Estoy con ellos 24 horas. Tenemos nuestra propia cultura y queremos conservarla para nuestros hijos. (Mujer casada, 36 años)

Por otro lado, en cuanto a las diferencias observadas con respecto a la mantención o aceptación de las prácticas culturales, se visibiliza el estado civil de los refugiados como un elemento clave en este aspecto, pues aquellos solteros del grupo, hombres jóvenes que llegaron sin esposa, hijos u otro vínculo familiar (siendo estos unos pocos casos aislados), exponen la adopción de un estilo de vida más occidentalizado, distanciándose de ciertas normas que dictan la conducta y tradiciones, expresadas por ejemplo en el consumo de alcohol (prohibido en el mundo musulmán), en la asistencia a celebraciones en donde se consume cerdo (alimento prohibido por Mahoma), así como ir a "la disco a carretear" con amigos, entre otras prácticas mal vistas por el resto de los refugiados palestinos.

\section{El Islam en la vida de los refugiados palestinos}

En cuanto a las prácticas religiosas, aparece como recurrente en el discurso de los refugiados las oraciones diarias y las celebraciones de las fiestas religiosas, como el Ramadán, el Ayd o fiesta del cordero y la Achura. En estos eventos comparten con el resto de las familias de refugiados palestinos y con miembros de la comunidad musulmana chilena residente en Santiago. Sin embargo, existe una serie de elementos que dificultan la realización de dichas prácticas religiosas. En el caso de las familias residentes en la ciudad de La Calera, se señala la ausencia de una mezquita y la distancia geográfica con Santiago (ciudad en la que existe dicho centro religioso), como uno de los elementos que dificulta la asistencia de las familias y de los hombres a las actividades que ahí se realizan. A esto se suma al alto valor de los pasajes de la locomoción pública y la precariedad económica de las familias, lo que les impide realizar dicho gasto.

Otra dificultad se relaciona con las oraciones diarias, las que se ven limitadas por las jornadas laborales de los hombres, los cuales inicialmente tenían conflictos con sus empleadores por pedir permiso para rezar a ciertas horas, situación que en la mayoría de los casos es negada y por ende con el tiempo los refugiados dejan de insistir en dicha práctica. 
Es por esto que se visibiliza una disminución con respecto al cumplimiento de ciertos preceptos religiosos, dada la ausencia de una estructura institucional y entorno social que lo permita y exija. No obstante, los refugiados han empezado a organizarse en torno a la posibilidad de generar estos espacios y cubrir sus necesidades espirituales. Como bien se observa en San Felipe, en donde tras dos años desde la llegada de los refugiados se instaló una musala (mezquita más pequeña o casa de oración), gracias a las gestiones de la Mezquita de Santiago y a los mismos refugiados de San Felipe, quienes en conjunto arriendan una casa en donde funciona el centro de oración.

Destaca la migración a San Felipe de una familia de refugiados que inicialmente vivía en Santiago y cuyo jefe de hogar es Sheij (guía espiritual islámico), quien decidió instalarse en la ciudad para hacer funcionar la musala. Se aprecia en San Felipe, así, junto al establecimiento de locales de comida árabe, una apropiación y transformación del espacio publico por parte de los refugiados palestinos.

\section{CONCLUSIONES}

En cuanto a la integración sociocultural de los refugiados, se observa que en la mayoría de los casos ellos han mantenido sus prácticas religiosas y culturales, conservando su propia identidad cultural. Al respecto, se aprecia que tampoco se ha desarrollado un sentimiento de pertenencia en relación al país de acogida al no identificarse con el mismo. De igual forma, al rescatar las teorías con respecto a la integración política, no se observa la incorporación por parte de los inmigrantes a organizaciones sociales, instituciones políticas o proyectos reivindicativos. A su vez, la participación en actividades de la comunidad musulmana chilena y en la comunidad de descendientes palestinos es escaza y responde a situaciones puntuales.

En cuanto al idioma ha existido un aprendizaje de la lengua en función de los distintos espacios sociales en los cuales interactúan los sujetos, tales como el trabajo o el barrio. Dicha situación no ha gravitado en la pérdida del idioma de origen, el cual se considera fundamental en la reproducción de su cultura y religión, manteniéndose en el ámbito privado del hogar.

Respecto de la integración social, el mantenimiento de las prácticas culturales no ha incidido en la capacidad de los refugiados de construir redes de solidaridad y lazos de amistad, los cuales han contribuido a un mayor acercamiento de los refugiados hacia la cultura, costumbres e idioma del país de origen. Estas redes también han permitido la re- 
solución de distintas necesidades y la obtención de puestos de trabajo para los refugiados, siendo fundamentales en el caso de aquellos que iniciaron emprendimientos laborales, para el éxito de dichas estrategias familiares de integración laboral.

En lo que se refiere a la integración laboral, los refugiados que han desarrollado trabajos independientes han tenido un relativo éxito en términos económicos, superando su situación inicial de pobreza, mientras que aquellos que se desempeñan como dependientes han accedido a trabajos precarios, de baja remuneración y temporales, sufriendo períodos de cesantía y gran inestabilidad laboral, dado en parte por su baja cualificación profesional y por las características del mercado laboral chileno, sufriendo una movilidad social descendente en relación a sus condiciones de vida en el país de origen, lo que ha impedido la solvencia económica de las familias y por ende los ha llevado a una situación de pobreza y vulnerabilidad social.

En particular sostengo que el problema que se encuentra tras la integración social de los refugiados palestinos guarda relación con la precariedad laboral de las familias y, por ende, con el acceso a servicios básicos estratificados en función del ingreso. Esta situación afecta no solo a los inmigrantes y refugiados sino que a toda la población que se encuentra en la escala de estratificación socioeconómica más baja.

Finalmente, en cuanto a las problemáticas de integración social relacionadas con la política de refugio en Chile, resalta la inexistencia de políticas públicas y programas estatales orientados hacia la integración de los inmigrantes y refugiados en los diversos ámbitos de la vida social, cultural, económica y política. ${ }^{12} \mathrm{El}$ argumento que se utiliza para justificar esta situación es el reducido número de inmigrantes y refugiados en Chile, por ello se espera que las personas se incorporen a los programas y prestaciones sociales ya existentes, desconociendo las desiguales condiciones sociales, legales y administrativas en la cual se encuentran los inmigrantes y refugiados (Courtis 2009).

Por otro lado, la intervención directa y la implementación de programas focalizados para los refugiados es delegada a instituciones humanitarias no gubernamentales; dichas entidades cuentan con recursos financieros limitados, condicionando la cantidad de personas que pueden atender, así como la calidad y profundidad de sus intervenciones. A

12 Situación contradictoria, pues a pesar de que no se ha modificado la Ley de Extranjería (la que posee una orientación policial y de control), durante los gobiernos posteriores al régimen militar se ha desarrollado una gestión mucho más abierta y flexible a la inmigración, la que carece de políticas públicas que se ajusten a las necesidades y problemáticas de la población migrante y refugiada en Chile. 
su vez, la falta de recursos incide en que los equipos de trabajo sean reducidos y por ende no puedan resolver de manera eficaz la demanda de atención existente.

Hechas las consideraciones anteriores, cabe precisar que la Vicaría contó con recursos financieros y humanos para asesorar e implementar estrategias dirigidas a la integración social de los refugiados palestinos; no obstante, la falta de experiencia de intervención con población con las características psicosociales y culturales de los palestinos, así como la carencia de profesionales especializados en la tematica de refugio, fueron elementos que dificultaron el proceso. ${ }^{13}$ Esto no impide reconocer los logros obtenidos en algunas de las estrategias que implicaron mejorías en las condiciones de vida de los refugiados, tales como asesoría y recursos para microemprendimientos laborales y entrega de subsidios para la vivienda, entre otros. Es de destacar el aprendizaje que esta experiencia ha significado para las instituciones implicadas en el proceso de acompañamiento e integración de este grupo de refugiados.

\section{REFERENCIAS}

Alto Comisionado de las Naciones Unidas para los Refugiados (ACNUR). 2006. "Situaciones prolongadas de refugiados: la búsqueda de soluciones prácticas." Pp. 105-27 en La situación de los refugiados en el mundo. Barcelona: Icaria

Refugiados 136:4-13

2007. “¿Refugiado o inmigrante?, ¿por qué importa la diferencia?” Revista

Agar, Lorenzo y Nicole Saffie. 2005. "Chilenos de origen árabe: la fuerza de las raíces." Revista Miscelánea de Estudios Árabes y Hebraicos 54:3-27.

Basabe, Nekase, Anna Zlobina y Dario Páez. 2004. “Integración socio-cultural y adaptación psicológica de los inmigrantes extranjeros en el País Vasco." Cuadernos Sociológicos Vascos 15:1-136

Bello, Martha. 2001. Desplazamiento forzado y reconstrucción de identidades. Bogotá: ICFES. Blanco, Cristina. 1990. La integración de los inmigrantes en Bilbao. Bilbao: Ayuntamiento de Bilbao.

2002. "Los inmigrantes y su integración. Apuntes en torno a una creciente nebulosa de conceptos, modelos y políticas." Pp. 71-82 en La inmigración en España: contextos y

13 El rol de la Vicaría en relación al proceso de integración de los refugiados palestinos posee múltiples dimensiones y gran extensión; dicha temática es desarrollada en mayor profundidad en la tesis de pregrado desde la cual se desprende esta primera aproximación a los resultados. 
alternativas II, Actas del III Congreso sobre la inmigración en España. Granada: Laboratorio de Estudios Interculturales.

Bourdieu, Pierre. 1999. Meditaciones Pacalianas. Barcelona: Anagrama

Courtis, Corina. 2009. "Diagnóstico participativo sobre atención a solicitantes de asilo y refugio en Chile." Mesa de trabajo en materia de refugio solicitada por Consejo de Política Migratoria del Departamento de Extranjería y Migración del Ministerio del Interior, Chile.

Giménez, Carlos. 2002. "Planteamiento multifactorial para la mediación e intervención en contextos multiculturales: una propuesta metodológica de superación del culturalismo." Pp. 617-44, en La inmigración en España: contextos y alternativas II, Actas del III Congreso sobre la inmigración en España. Granada: Laboratorio de Estudios Interculturales.

Gualda, Estrella. 2001. Los procesos de integración social de la primera generación de "Gastarbeiter" españoles en Alemania. Huelva: Universidad de Huelva.

Sole, Carlota, et al. 2002. "El concepto de integración desde la sociología de las migraciones." Revista Migraciones 12:10-39.

Solé, Carlota, Faustino Miguelez, Rosa Junyenet y Antonio Izquiedo. 1979. “Aproximación al problema de la integración sociocultural de los inmigrantes en Cataluña." Papers de Sociología 11:81-96.

Soriano, Rosa y Carmen Santos. 2002. "El perfil social de la mujer inmigrante marroquí en España y su incidencia en la relacion intercultural.” Papeles de Geografía 36:171-84.

Soriano, Rosa. 2006. "La inmigracion femenina marroquí y su asentamiento en España." Revista Internacional de Sociología LXIV (43):169-91.

Torres, Francisco. 2005. "De la asimilacion al pluralismo. Inmigracion y gestión de la diversidad cultural en las sociedades contemporáneas." Arxius de Ciencies Socials 11:61-87

Vicaría de la Pastoral Social y de los Trabajadores. 2010. Perfil de egreso de las familias palestinas en relacion al programa de reasentamiento humanitario. Santiago: Vicaria de la Pastorial Social y de los trabajadores (documento interno)

Wengert, Gabriela y Michelle Alfaro. 2007. “PPueden los refugiados palestinos en Iraq encontrar protección?" Migraciones Forzadas 26:19-22. 